\title{
Identification of the geographical extent of an area benefiting from a transportation project: A generalized synthetic control
}

\author{
Takara Kunimi \\ Kyoto University \\ kunimi.takara.75m@st.kyoto-u.ac.jp
}

\author{
Hajime Seya (corresponding author) \\ Kobe University \\ hseya@people.kobe-u.ac.jp
}

\begin{abstract}
In evaluating the benefits of an infrastructure project, it is essential to consider who is benefiting from the project and where benefits are located. However, there is no established way to accurately determine the latter. To fill this methodological gap, this study proposes an approach for the ex-post identification of the geographical extent of an area benefiting from a transportation project based on a generalized synthetic control method. Specifically, it allows comparing multiple treatment units with their counterfactuals in a single run-changes in land prices (actual outcome) at each treated site are compared to the counterfactual outcome, and the individual (i.e., unit-level) treatment effect on the treated site is then estimated. This approach is empirically applied to a large-scale Japanese heavy railway, the Tsukuba Express line project. Our approach enables the detection of 1) the complicated spatial shape of benefit incidence; 2) negative spillovers; and 3) the increase in options (train routes), typically not considered in a benefit evaluation system based on the hedonic approach, but which can be capitalized into land prices.
\end{abstract}

Keywords: Ex-post evaluation, transportation project, benefit evaluation, generalized synthetic control method, land prices

\section{Article history:}

Received: April 29, 2020

Received in revised form: August 14, 2020

Accepted: September 22, 2020

Available online: January 5,

2021

\section{$1 \quad$ Introduction}

In evaluating the benefits of an infrastructure project, it is often essential to consider not only the total benefit amount but also the benefits' incidence or distribution. Regarding the latter, two questions are commonly raised: (1) who is benefiting from the infrastructure project and (2) where is the benefit located? To answer the first question, especially in Japan, the benefit incidence matrix proposed by Morisugi and Ohno $(1992,1995)$ is widely used to capture benefit incidence among agents such as households, firms, landlords, and governments under the framework of general equilibrium modeling. ${ }^{1}$ However, there is no established way to capture spatial benefit distribution (i.e., placement). This study, therefore, focuses on the second question from the viewpoint of ex-post project evaluation.

Although the effects of transportation projects on land use and urban development may take a relatively long time to observe, the impact of such projects on property value is likely to manifest over

\footnotetext{
${ }^{1}$ Additionally, studies on the associations between transportation and gentrification have made significant contributions to answering the first question (Padeiro, Louro, \& da Costa, 2019).

Copyright 2021 Takara Kunimi \& Hajime Seya

http://dx.doi.org/10.5198/jtlu.2021.1784

ISSN: 1938-7849 | Licensed under the Creative Commons Attribution - Noncommercial License 4.0
}

The Journal of Transport and Land Use is the official journal of the World Society for Transport and Land Use (WSTLUR) and is published and sponsored by the University of Minnesota Center for Transportation Studies. 
a shorter period (Seya \& Timmermans, 2018). Hence, it is useful to focus on property value, expressed through indicators such as land and housing prices (Debrezion, Pela, \& Rietveld, 2007). Assessing the impact of transportation projects on property value is also important for financing transport infrastructure via value capture. Note that a railway opening can have not only a positive impact due to changes in accessibility, but also a negative impact. For instance, Geng, Bao, and Liang (2015) empirically analyzed the effects of high-speed rail on house prices in Beijing and found that house prices increase with a decline in the distance between houses and high-speed rail stations within $(0.891 \mathrm{~km}, 11.704 \mathrm{~km})$. Nevertheless, house prices declined with a decline in the distance between houses and high-speed rail stations within $(0.475 \mathrm{~km}, 0.891 \mathrm{~km})$. They concluded that traffic congestion, electromagnetic radiation pollution, noise, and higher crime rates may negatively affect prices of houses located close to highspeed rail stations. Our method can detect such negative impacts as well.

According to Dubé, Thériault, and Des Rosiers (2013), who focused on the effects of commuter rail accessibility on house prices, methods to measure the proximity effects based on the hedonic approach can be categorized into: 1) dummies based on distance (or travel time) cut-off criteria that generate ring buffers around stations or along service routes; 2) continuous measures of distance (or travel time) from each house to the nearest station; and 3) mixed approaches that combine both categories. For instance, the method proposed by Gibbons and Machin (2005) may be included in the second category, as they identified a useful figure, where the kernel regression of residual prices is plotted against the distance to railway stations in $\mathrm{km}$ (grid points). ${ }^{2}$ However, since the spatial distribution patterns of benefits could be complicated, an isotropic assumption is sometimes not realistic. ${ }^{3}$ Further, Seya, Yoshida, and Tsutsumi (2016) captured intricate spatial distribution patterns by clustering the changes in land prices before, during, and after a project at micro district level using functional k-means. However, this method does not allow for a statistical inference on the changes.

To fill this literature gap, we propose a new method for the ex-post identification of the geographical extent of an area benefiting from a transportation project by applying Xu's (2017) generalized synthetic control (GSC) method. The GSC method enables the comparison of multiple treatment units with their counterfactuals in a single run and the estimation of the individual (i.e., unit-level) treatment effect on the treated (ITT), which is an extreme case of a heterogeneous treatment effect (on the treated), and its uncertainty. This approach is more advantageous than the traditional difference-in-differences approach, which estimates only the homogeneous average treatment effect on the treated (ATT). ${ }^{4}$ We then empirically apply the GSC-based approach to a large-scale Japanese heavy railway, the Tsukuba Express (TX) line project.

The remainder of this paper is organized as follows. Section 2 reviews the related literature. Section 3 introduces the GSC method. Section 4 presents the results of our empirical analysis. Finally, Section 5 concludes the paper.

\section{$2 \quad$ Literature review}

Thus far, various studies have been conducted on the impact of transport on land use or property prices (for a review of Asian examples, see Seya \& Timmermans, 2018). For example, Cervero and Landis (1995) noted that, for developed countries, although new transportation investments no longer shape urban cities by themselves, they remain vital in channeling growth and determining the spatial extent of metropolitan regions through their joint effects with policies such as supportive zoning and government-

\footnotetext{
2 Residual prices are estimated as residual from an ordinary least squares regression of log-prices on the controls.

3 Directionally varying methods are applied by Cameron (2006).

${ }^{4}$ See Kuminoff and Pope (2014) for the welfare theoretic interpretation of the ATT regarding the impacts of public programs on the housing market.
} 
assisted land assembly. Ewing (2008) extended this discussion to a highway context and suggested that, even if the net economic impacts (which he termed the "aggregate impact" of highway investments) are small, highways may have significant impacts on the geographic pattern of development within a region (which he called "localized impacts"). The TX line connects Akihabara district of the Tokyo Prefecture to Tsukuba city, ${ }^{5}$ Ibaraki Prefecture; it has a length of $58.3 \mathrm{~km}$ and commenced operation on August 24, 2005. Seya et al. (2016) discussed that the overall impact of this line may be a mix of generative (aggregate) and redistributive (localized) impacts because, although the line is located in a developed country (Japan), it has reduced the travel time from Akihabara to Tsukuba from 85 minutes (using the existing Japan Railways [JR] Joban line or a highway bus) to 45 minutes. Although existing studies suggest that local development does not always occur around transportation cores (e.g., Handy, 2005), in the case of the TX line, various urban improvements or development projects have been undertaken near new stations. Japan's "Act on Special Measures Concerning [the] Comprehensive Advancement of Housing Development and Railway Construction in Metropolitan Areas" ensures such developments. This law harmonizes the construction of railway lines and urban planning around stations, including the technique of land readjustment (e.g., Sorensen, 2001). Hitherto, it has only been applied to the TX line. Several studies have examined land prices around the TX line, including Pior, Shimizu, and Nakamura (1998), Pior and Shimizu (2001), Tsutsumi and Seya (2009), which used the hedonic approach to evaluate the benefits of the TX line project, and Ahsan, Nakamura, and Ueda (2001), which employed an integrated land-use transportation model for this purpose.

Based on our literature review, only Seya et al. (2016) attempted an ex-post assessment of the TX line project focusing on land prices. ${ }^{6}$ They found that land prices rose around TX stations with rapid train stops (i.e., Moriya and Tsukuba stations) from 2005 to 2009 (or 2008) and began to decrease from 2009, while land prices around the Kanto Tetsudo Joso line (hereafter, Joso line) were reasonably constant over the target period (a type of complementary effect). Meanwhile, land prices decreased around the JR Joban line (a type of substitution effect or negative spillover due to competition). ${ }^{7}$ Thus, according to Handy (2005), they may have identified a redistributive impact. Nonetheless, we do not know whether such a negative spillover is statistically significant. Generally, negative spillover effects are difficult to capture without travel behavior data. ${ }^{3}$ Therefore, these effects are typically ignored in an exante benefit evaluation system based on the hedonic approach (Tsutsumi \& Seya, 2009). However, it is practically important to understand the presence and degree of such effects. This study tries to refine Seya et al.'s (2016) analyses via the GSC method.

\section{Generalized synthetic control method}

We employ the GSC method following Xu (2017), who developed it to make causal inferences under the framework of interactive fixed effects modeling (Bai, 2009). The estimation procedure of the GSC method $(\mathrm{Xu}, 2017)$ differs from that of the interactive fixed effects to be applied for counterfactual impact evaluation. The interactive fixed effects model is one of the regression models used for panel analysis, which models unobserved time-varying confounders semi-parametrically.

Assume $Y_{i t}$ is the outcome of interest of unit $i$ at time $t$, and $\mathcal{T}$ and $\mathcal{C}$ denote the sets of units in the treatment and control groups, respectively. The total number of units is $N=N_{t r}+N_{c o}$, where $N_{t r}$ and $N_{c o}$ are the numbers of treated and control units, respectively. All units are observed for $T$ periods (from time 1 to $T$ ), covering the $T_{0}$ control period prior to the opening and the $q=T-T_{0}$ evaluation period. An

\footnotetext{
5 Tsukuba City is one of Japan's hub towns for research and science.

6 Mizutani (2012) empirically verified land-use changes around the TX station.

7 See subsection 4.2 regarding these lines.

8 Kawada et al. (2010) investigated travel behavior change after the TX line became operational.
} 
econometric model for the GSC method can be formulated as follows:

$Y_{i t}=\delta_{i t} D_{i t}+\boldsymbol{x}_{i t}^{\prime} \boldsymbol{\beta}+\boldsymbol{\lambda}_{i}^{\prime} \boldsymbol{f}_{t}+\varepsilon_{i t^{\prime}}$

where $Y_{i t}$ is an outcome; $D_{i t}$ is the treatment indicator that takes 1 if $i \in \mathcal{T}$ and $t>T_{0}$, and 0 otherwise; $\boldsymbol{x}_{\text {it }}$ is a $k \times 1$ time-varying covariate vector; $\boldsymbol{\beta}$ is a corresponding $k \times 1$ regression coefficient vector; and $\varepsilon_{i t}$ is a zero-mean independent and identically distributed (i.i.d.) error term. Different from conventional (panel) regression models, the GSC method has terms $\lambda_{i}^{\prime} \boldsymbol{f}_{t}$ and $\delta_{i t} D_{i t}$ where $\boldsymbol{\lambda}_{i}$ is an $r \times 1$ vector of common factors and $\boldsymbol{f}_{t}$ is an $r \times 1$ vector of factor loadings. In scalar form, $\boldsymbol{\lambda}_{i}^{\prime} \boldsymbol{f}_{t}$ can be written as $\lambda_{i}^{\prime} \boldsymbol{f}_{t}=\lambda_{i 1} f_{1 t}+\ldots+\lambda_{i r} f_{r t}$. Note that when we set $f_{1 t}=1$ and $\lambda_{i 2}=1$ with $\delta_{i t}=0$ and $r=2$, term $\boldsymbol{\lambda}_{i}^{\prime} \boldsymbol{f}_{t}$ is reduced to $\lambda_{i 1} f_{2 t}$. Therefore, we have a conventional two-way fixed effects model $\left(Y_{i t}=\boldsymbol{x}_{i t}^{\prime} \boldsymbol{\beta}+\lambda_{i 1}+\right.$ $\left.f_{2 t}+\varepsilon_{i t}\right)$. In this sense, the interactive fixed effects model is an extension of the two-way fixed effects model. Term $\boldsymbol{\lambda}_{i}^{\prime} \boldsymbol{f}_{t}$ may capture a wide range of unobserved heterogeneity. ${ }^{9}$ Moreover, when we set $\delta_{i t}=$ 0 , Equation (1) is reduced to the standard interactive fixed effects model $\left(Y_{i t}=\boldsymbol{x}_{i t}^{\prime} \boldsymbol{\beta}+\boldsymbol{\lambda}_{i}^{\prime} \boldsymbol{f}_{t}+\boldsymbol{\varepsilon}_{i t}\right)$. Thus, the GSC method can be understood as a bias correction procedure for interactive fixed effects models when the treatment effect is heterogeneous across units (Xu, 2017).

Based on the potential outcome framework, let $Y_{i t}(1)$ and $Y_{i t}(0)$ be the potential outcomes under $D_{i t}=1$ and $D_{i t}=0$, respectively. Now, we have $Y_{i t}(1)=\delta_{i t}+\boldsymbol{x}_{i t}^{\prime} \boldsymbol{\beta}+\boldsymbol{\lambda}_{i}^{\prime} \boldsymbol{f}_{t}+\varepsilon_{i t}$ and $Y_{i t}(0)=\boldsymbol{x}_{i t}^{\prime} \boldsymbol{\beta}+\boldsymbol{\lambda}_{i}^{\prime} \boldsymbol{f}_{t}+\varepsilon_{i t}$, which indicates that, for unit $i$ in year $t$, ITT $\equiv \delta_{i t}$ for any $i \in \mathcal{T}, t>T_{0}$. Moreover, for year $t$, ATT $\equiv$ $\left(\sum_{i \in T} \delta_{i t}\right) / N_{t r^{\prime}} \mathrm{Xu}(2017)$ showed that $\delta_{i t}$ can be estimated using the three steps least squares method and the inference on $\delta_{i t}$ can be made via the parametric bootstrap method. The number of factors, $r$, can be determined through cross-validation. However, this paper does not discuss the estimation procedures in detail because no methodological innovation is presented; please refer to $\mathrm{Xu}$ (2017) for the actual procedures. In the following empirical analysis, time-varying covariates, $\boldsymbol{x}_{i t}^{\prime} \boldsymbol{\beta}$, are removed due to a lack of data that can be observed annually at the scale of the unit. We use the R package gsynth for our analysis. The number of factors is automatically calibrated in this package via cross validation. ${ }^{10}$

\section{$4 \quad$ Empirical analysis}

\subsection{Generalized synthetic control method to identify the geographical extent of an area benefiting from a transportation project}

Based on the GSC method, we conduct an ex-post identification of the geographical extent of an area benefiting from a transportation project. To this end, we prepare a panel of land prices observed before, during, and after the project in the potentially impacted areas (i.e., treatment group) and those not impacted (i.e., control group/donor pool). We then apply the GSC method, compare the changes in land prices (actual outcome) at each treated site to the counterfactual outcome, and estimate the ITT. Parametric bootstrap is employed to estimate the uncertainty of the IT'Ts.

\subsection{Study area and the definitions of treatment and control groups}

The target of this study is a large-scale Japanese heavy railway—-the TX project. The TX project was

\footnotetext{
9 It cannot capture unobserved confounders that are independent across units.
}

10 The dataset and code are available from the corresponding author upon request. 
formulated by Japan's Ministry of Land, Infrastructure and Transport (MLIT) in 1999. Construction commenced in 2001 and operation in 2005. The TX line passes through four prefectures (see Figure 1): Tokyo (Chiyoda, Taito, Arakawa, and Adachi wards), Saitama (Yashio and Misato cities), Chiba (Nagareyama and Kashiwa cities), and Ibaraki (Moriya, Tsukubamirai, and Tsukuba cities). We chose Ibaraki as the study area, in line with Seya et al. (2016), as sites here would obtain larger benefits because there was no rail connectivity for most areas along the TX line. Thus, the impact of the TX line is expected to be significant. ${ }^{11}$

Our study area comprises treatment and control areas (Figure 2). The treatment area comprises [A] the municipalities that the TX line passes through in Ibaraki Prefecture and $[\mathrm{B}]$ the outer adjacent municipalities in this prefecture (termed as first-order adjacent areas). Outer adjacent municipalities to [B] in Tochigi and Ibaraki prefectures are defined as the control area [C] (termed as second-order adjacent areas). The set of units in the treatment area is the treatment group $(\mathcal{T})$ and those in the control area, the control group $(\mathcal{C})$. In our study area, two railway lines other than the TX line exist- the Joso line, which is a relatively small-scale intra-prefecture non-electrified railway line that passes through the west side of the study area, ${ }^{12}$ and the Joban line, which is a relatively large-scale inter-prefecture railway line that connects Tokyo and the Tohoku region (Figure 1). Note that, while the empirical analysis focused mainly on Ibaraki, we also present the impact on Chiba for comparison. Chiba had several existing railway services before the TX line opened; thus, the impact in this prefecture is expected to be smaller.

The control area is more countrified than the treatment area, and there was no big (re-)development project over the study period (see subsection 4.3). Tsutsumi and Seya (2008) showed that using outer adjacent municipalities for the control group could conclusively reveal the effects of opening the TX line. The following analysis results confirm that the impacts of the opening of the TX line are rather localized and do not extend to the control group.

${ }^{11}$ Our trial analyses suggest that it is challenging to identify the effect of the opening of the TX line when all four prefectures are considered.

${ }^{12}$ At the Moriya Station, the TX and Joso lines are interchanged. However, there are no "trackage rights" for either line. 


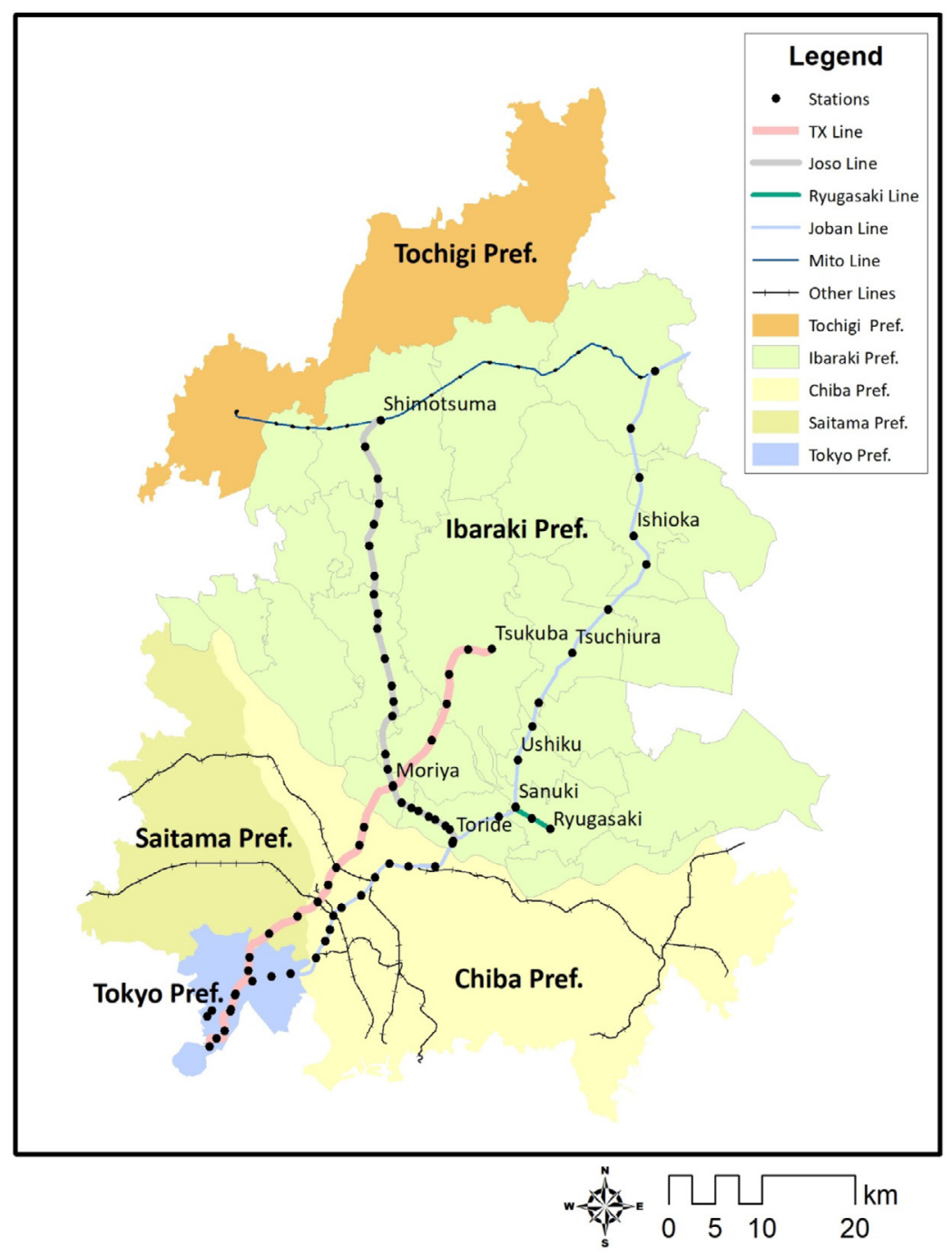

Figure 1. Location of the TX line 


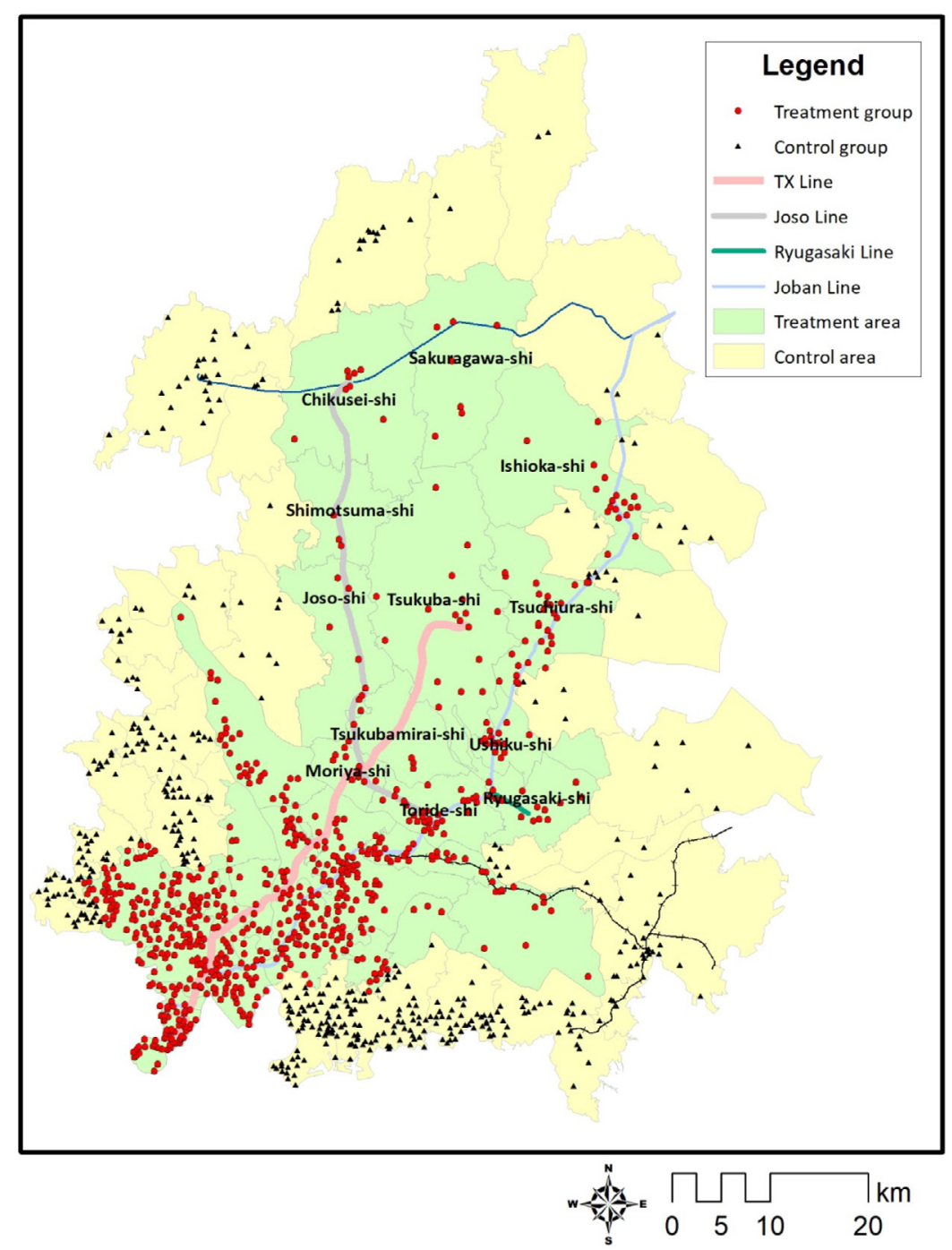

Figure 2. Treatment and control groups

\subsection{Data and study period}

Several types of land price data exist in Japan. Using market transaction prices, which are devoid of appraisal bias, is the best practice. However, to ensure privacy, the locations of transactions and actual transaction prices are not disclosed to researchers. Moreover, only approximate information on locations and prices is available. Furthermore, the sample size is too small for our analysis, and the locations of transactions differ from year to year. Hence, we use officially assessed land prices, which provide information regarding appraisal land prices (Shimizu \& Nishimura, 2006). Note that the changes in the assessed land prices are mild compared to those in the transaction land prices. Thus, our analysis results may indicate the minimum values of the effects of the opening of the TX line. ${ }^{13}$

13 http://www.mlit.go.jp/en/totikensangyo/totikensangyo_fr4_000001.html 
The Land Appraisal Committee under the MLIT publishes market values per square meter of standard sites annually on January 1. The Committee's Land Market Value Publication has provided the necessary information on the land market in Japan since 1970. The locations of the standard sites often change and new sites are added around the opening of railway stations. Nevertheless, we limit our analyses to sites with continuously observed land prices from 1994 to 2011 because of the lack of reliable methods to address the situation where observed sites change frequently or where the outcome is available only for post- (or pre-) intervention. It is possible to impute the missing data using, for instance, kriging (Yamagata \& Seya, 2019) and create a pseudo complete dataset. However, the accuracy of the interpolation will influence the results and it is not easy to assess the impact of incorporated bias.

We choose 1994 and 2011 by considering the balance between sample size and pre- or post-intervention lengths. Since the TX project was formulated in 1999, 1994 (11 years before the opening) would be an adequate starting point. We select 2011 as the ending point because on March 11, 2011, "the Tohoku Earthquake" damaged our study area heterogeneously. Thus, many standard sites had to be replaced. For simplicity, we focus on the opening effects and do not consider announcement effects (Tsutsumi \& Seya, 2008). Changes in average land prices in each category, defined by the distance band from the TX stations, are shown in Figure 3. The parentheses after the distance band denote the numbers for each case. Figure 3 indicates that there may be a positive impact on land prices within 3 $\mathrm{km}$ from the TX stations.

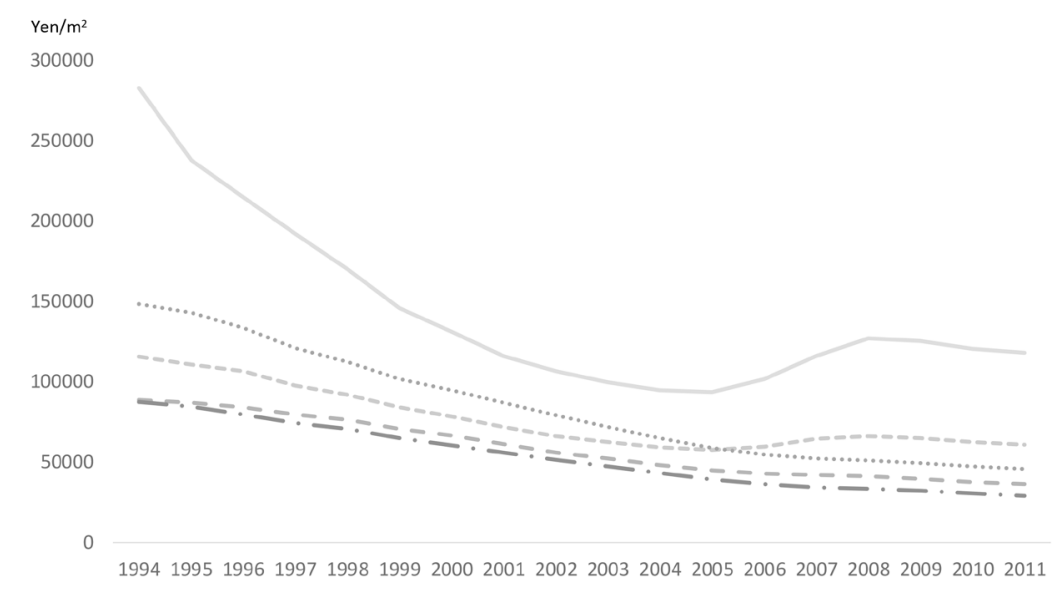

Figure 3. Changes in average land prices in each category, defined by the distance band from the TX stations

\subsection{Results}

\subsubsection{Estimation of ATT}

Here, we present the estimate for the ATT of the opening of the TX line. While the empirical analysis focuses mainly on Ibaraki, this subsection presents the results for Chiba for comparison.

We extract the treatment and control areas in Ibaraki and Chiba and analyze them using the GSC method. As stated in subsection 4.2, the treatment group consists of the units in the treatment area (the municipalities that the TX line passes through and those in their first-order adjacent areas, that is, 169 sites) and the control group consists of the units in the control area (second-order adjacent municipalities, that is, 53 sites). Figures 4 and 5 show the actual changes in average land prices in the treatment group (solid line) and the counterfactual changes in average land prices (dotted line) for Ibaraki and Chiba, respectively. We can see that the average for the treatment group closely matches that of the 
counterfactual at the $5 \%$ level at time t before the opening of the TX line in both groups ("Estimated $Y(0)$ average" in Figures 4 and 5).

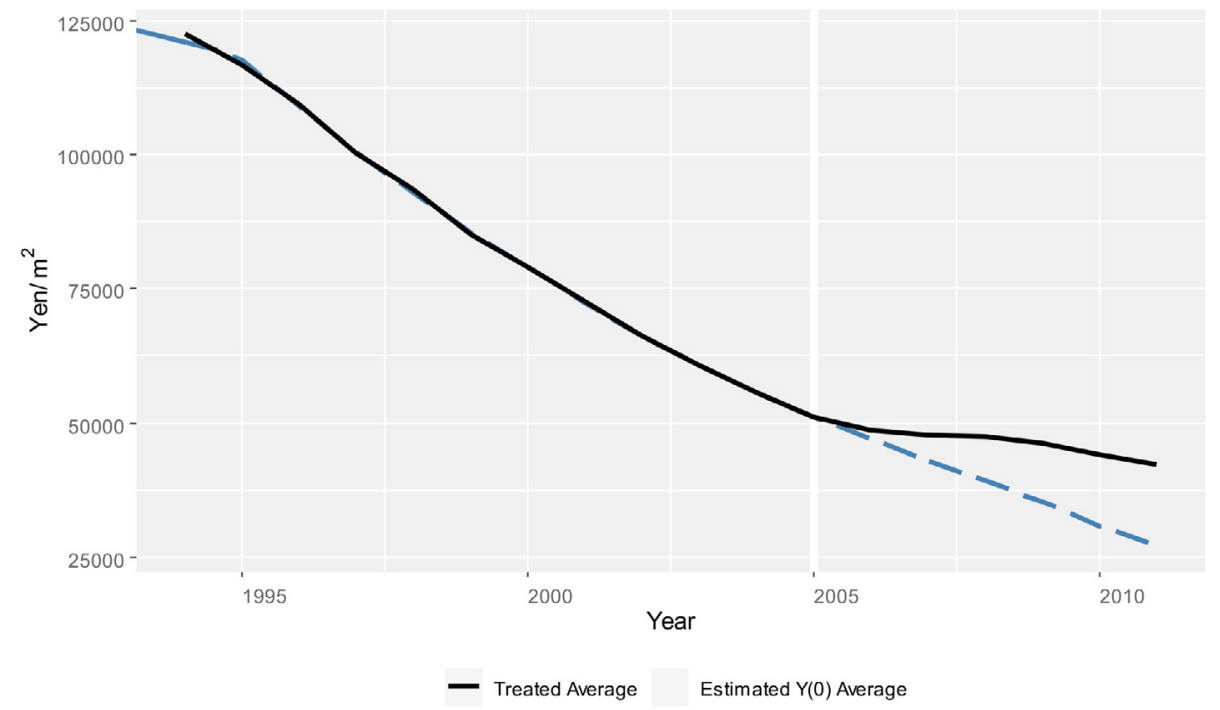

Figure 4. ATT in Ibaraki Prefecture

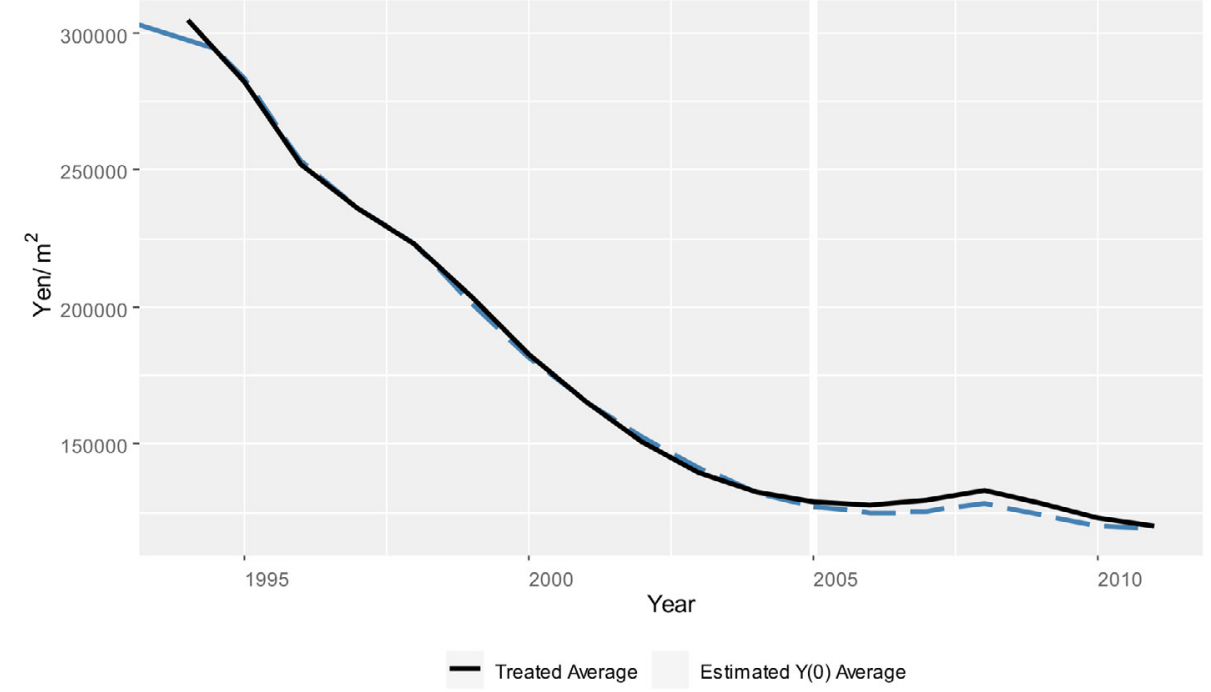

Figure 5. ATT in Chiba Prefecture

Ibaraki's results (Figure 4) reveal a positive ATT after the opening of the TX line. Given the decrease in land prices in the pre-opening study period, the opening of the TX line would absorb that drop. The

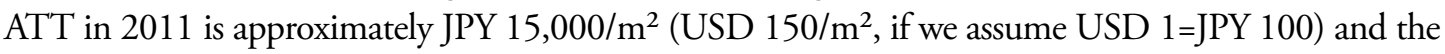
average land price in the treatment group in 2011 is approximately JPY $42,400 / \mathrm{m}^{2}$. Hence, the most significant causal effect of the opening of the TX line on the increase in land prices is approximately $35 \%$, which is high. 
Meanwhile, while Chiba's results (Figure 5) show a positive ATT from 2006 to 2011 due to the opening of the TX line, its magnitude is less than that of Ibaraki. The ATT in 2008, when the effect was at its peak, is approximately JPY $4,700 / \mathrm{m}^{2}$ (USD $47 / \mathrm{m}^{2}$, if we assume USD $1=\mathrm{JPY} 100$ ), while the average land price in the treatment group in 2008 is approximately JPY $133,400 / \mathrm{m}^{2}$. Hence, the most significant causal effect of the opening of the TX line on the increase in land prices was no greater than approximately $3.7 \%$. As previously stated, these results are expected, since the treatment area in Ibaraki was not served by rail for many years.

\subsubsection{Estimation of ITT}

Here, we report the $p$-values in the inference of the estimated ITT for Ibaraki (Figures 6-11, each of which corresponds to 2006-2011, respectively). Color and size have been used to distinguish the points for each unit, indicating whether the ITT is positive or negative, as well as the significance levels $(1 \%$, $5 \%$, or $10 \%)$. A .gif animation of Figures 6-11 is shown in the appendix to better understand the temporal change.

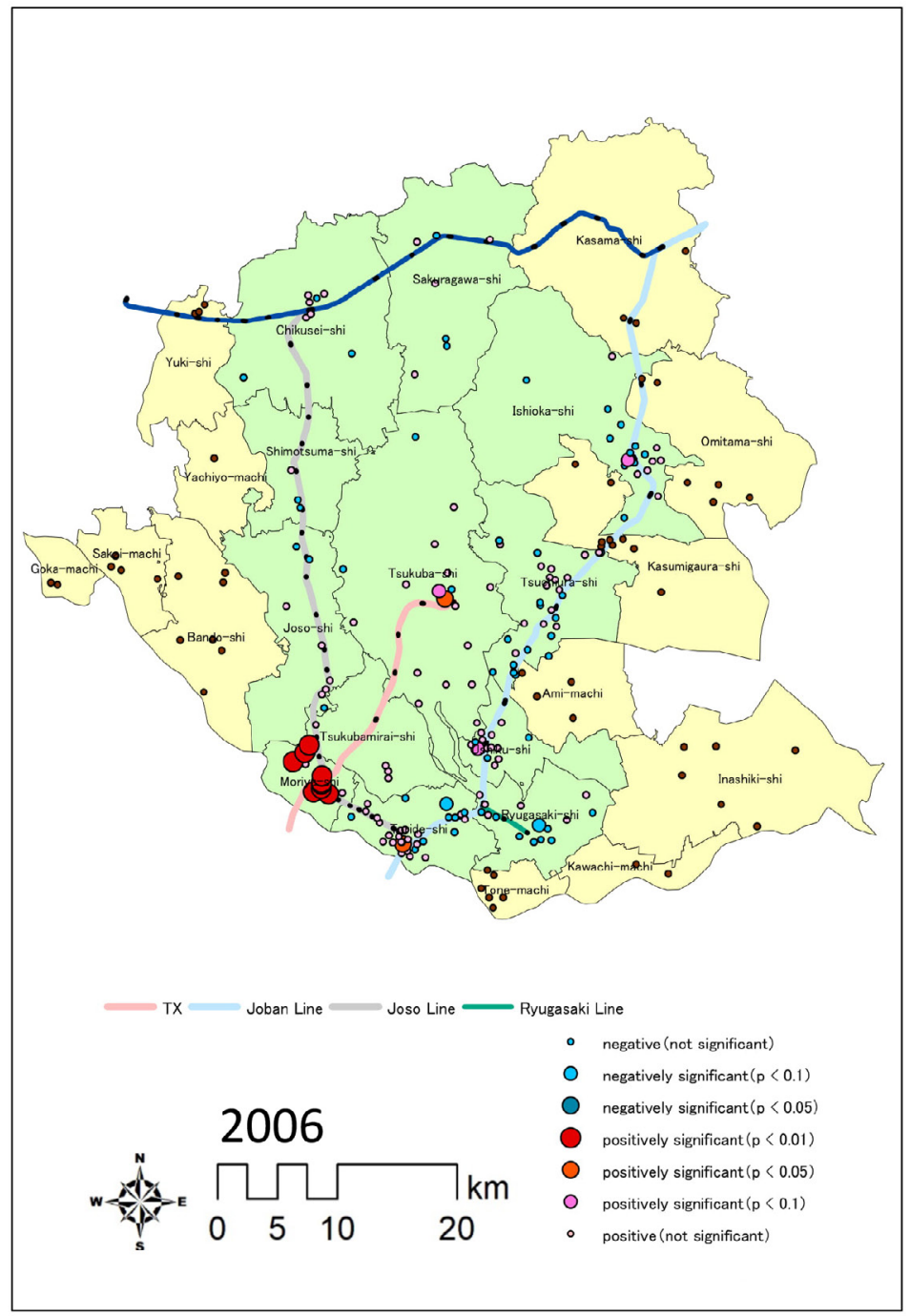

Figure 6. P-values of the ITTs in Ibaraki Prefecture for year 2006 


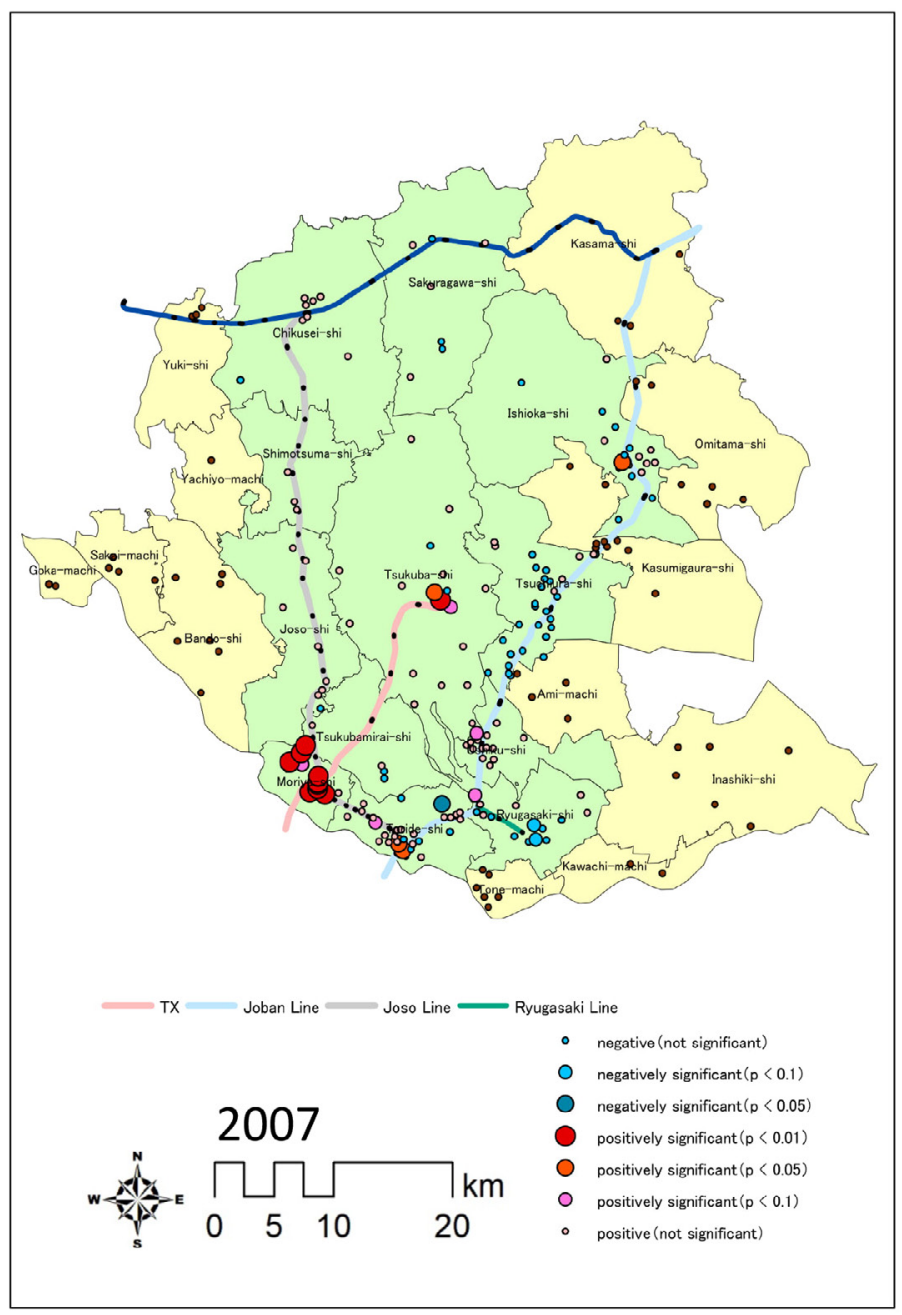

Figure 7. P-values of the ITTs in Ibaraki Prefecture for year 2007 


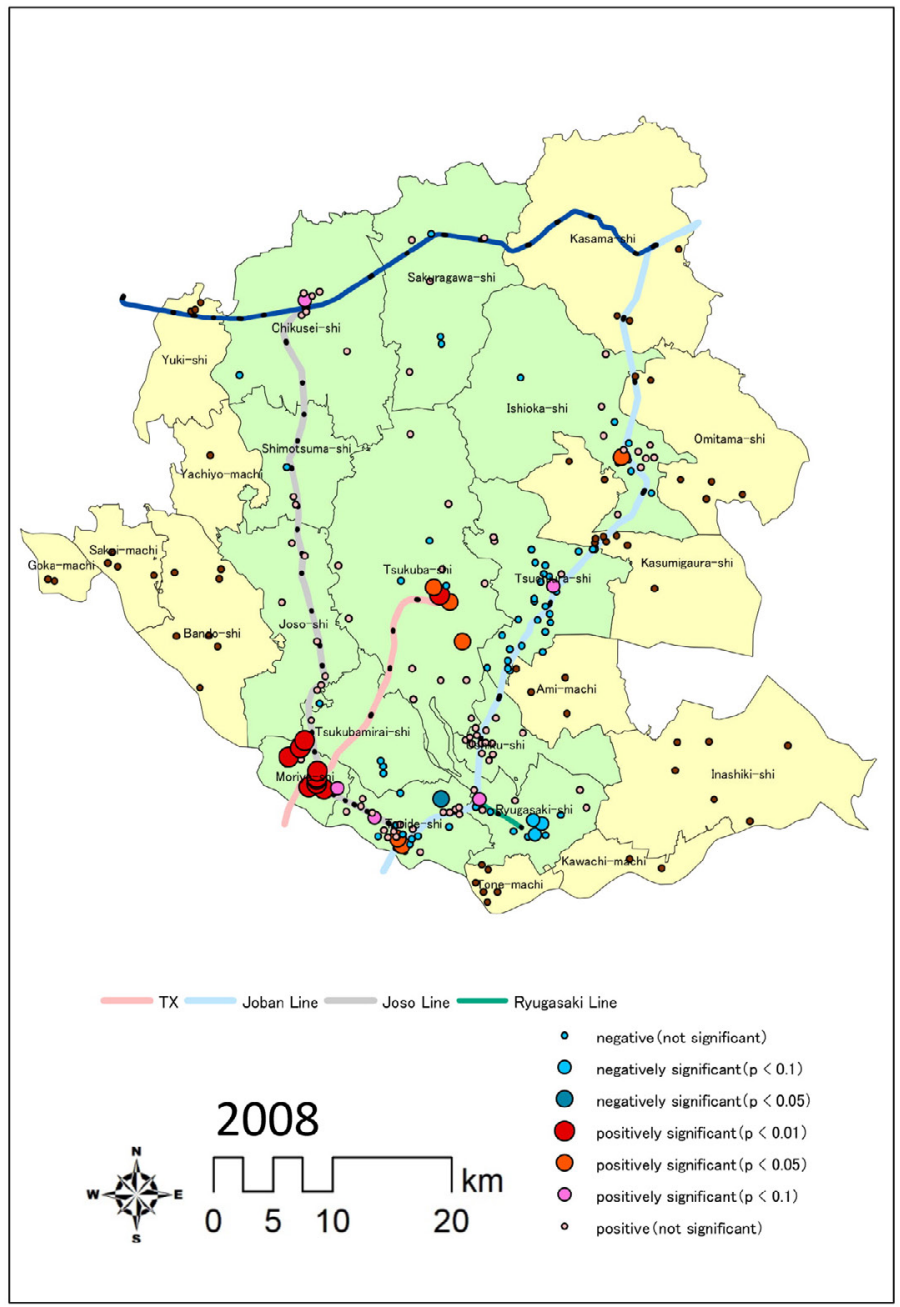

Figure 8. P-values of the ITTs in Ibaraki Prefecture for year 2008 


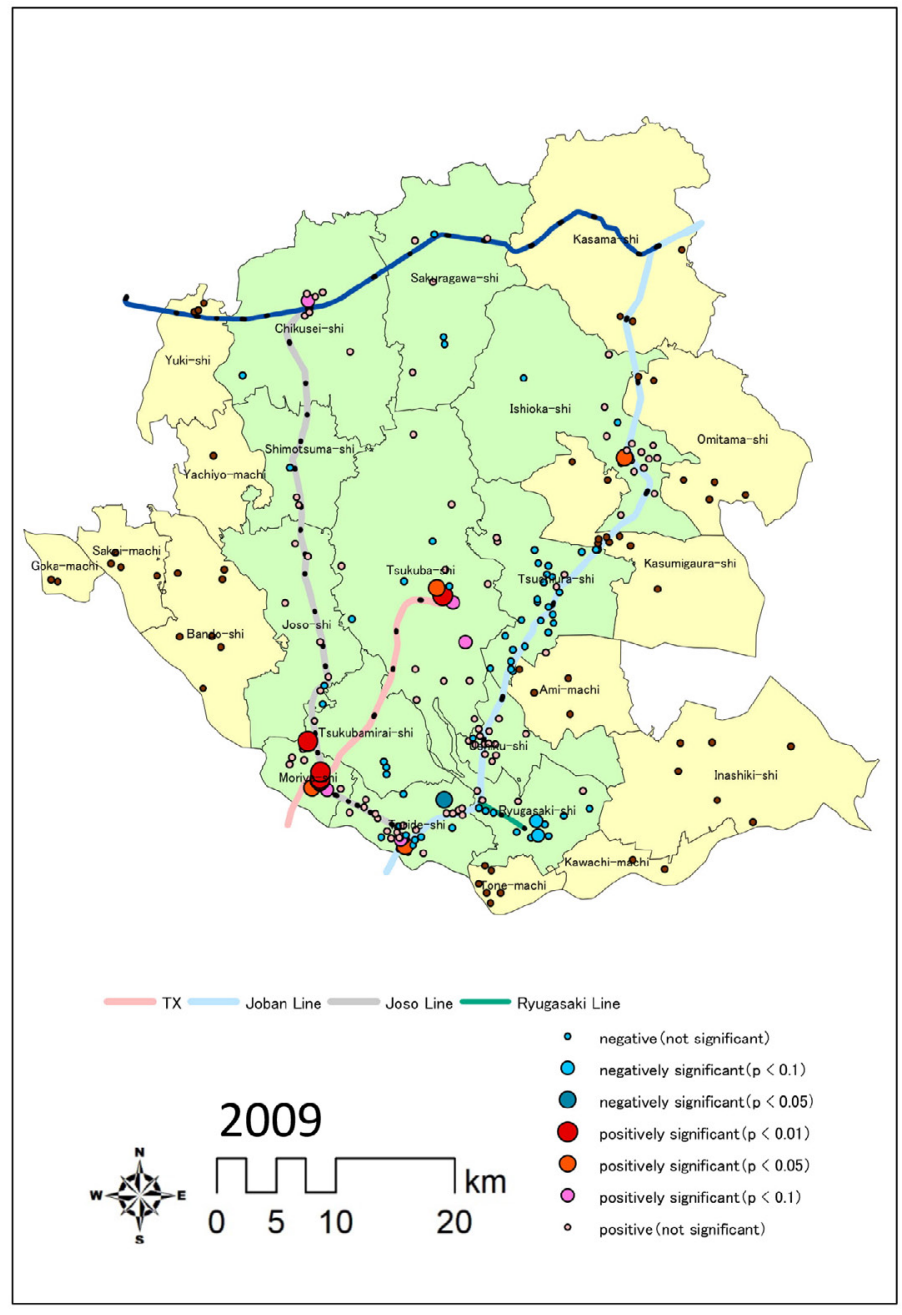

Figure 9. P-values of the ITTs in Ibaraki Prefecture for year 2009 


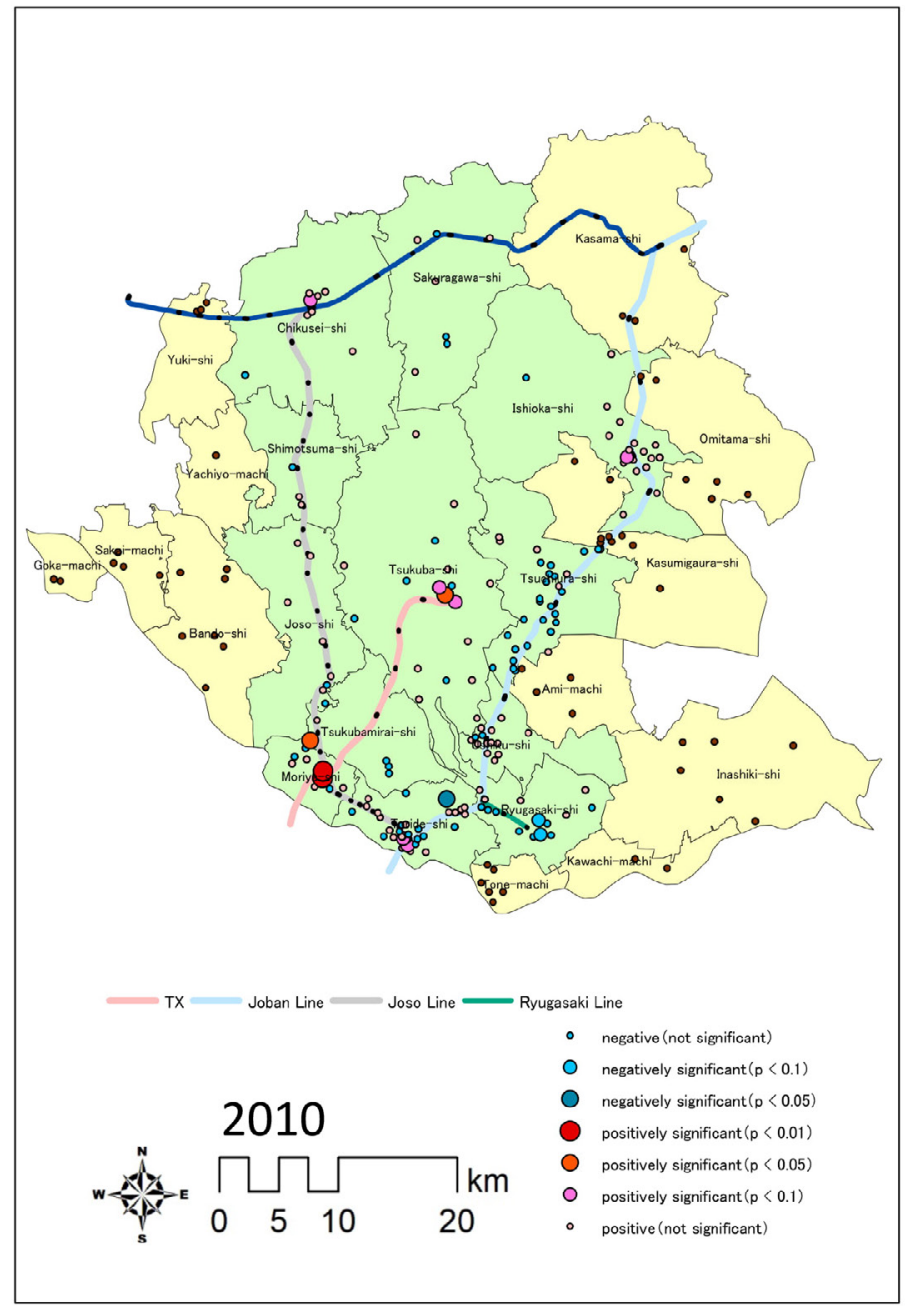

Figure 10. P-values of the ITTs in Ibaraki Prefecture for year 2010 


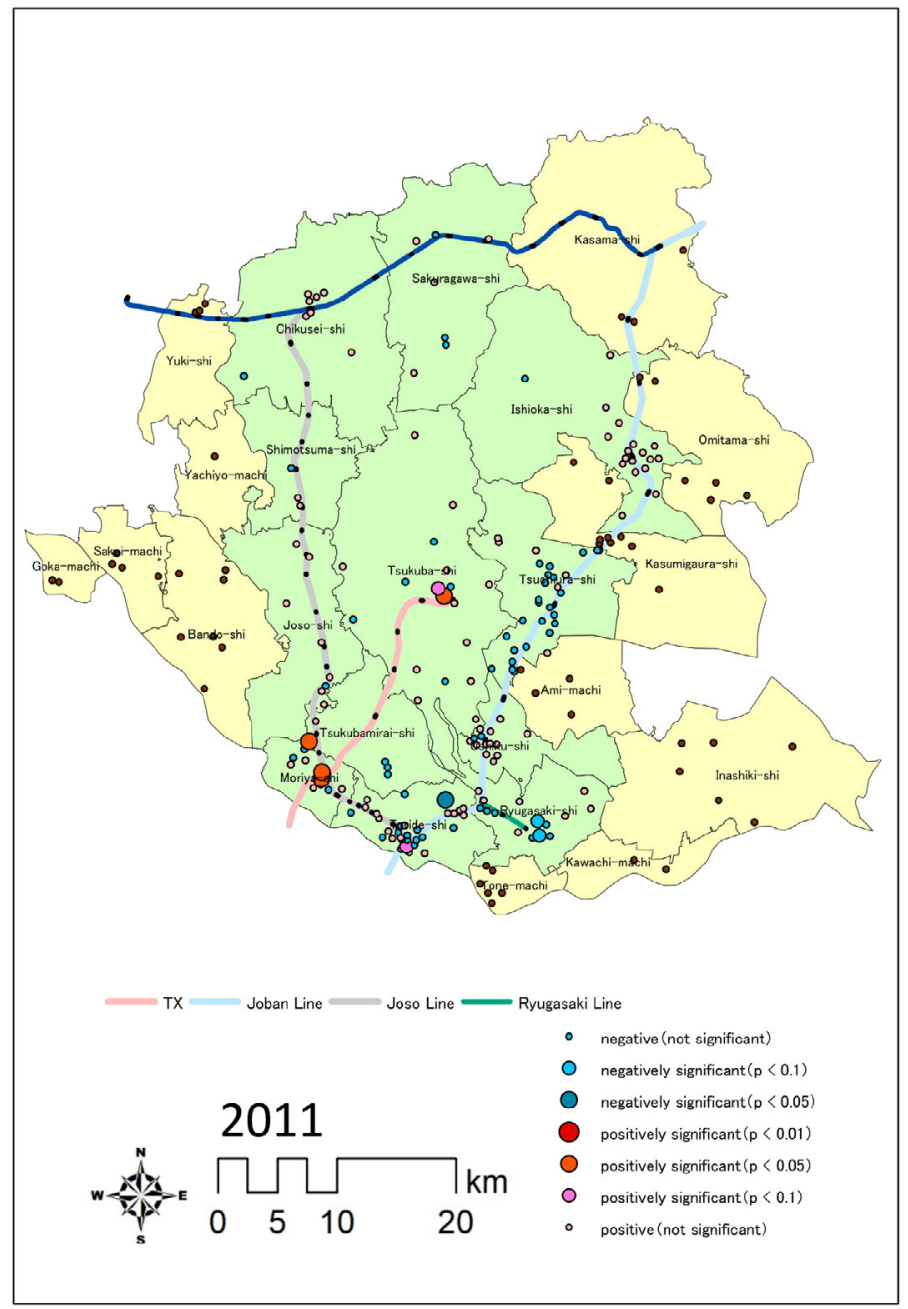

Figure 11. P-values of the ITTs in Ibaraki Prefecture for year 2011

\section{Estimation results}

We observe striking treatment effects in the area around Moriya Station, which became a transfer station for the TX and Joso lines, as well as the area around Tsukuba station, which is a terminus of the TX line (see Figure 1). This result is in line with Seya et al. (2016), although our study has the advantage of explaining the geographical distribution of statistically significant points by considering $\mathrm{p}$-values. While Seya et al. (2016) highlighted the increase in land prices around Mt. Tsukuba, our estimates show that the increase did not have a significant effect.

A significantly positive treatment effect at the $1 \%$ level was observed in many of the areas around Moriya Station between 2006 and 2010. In 2011, a significantly positive treatment effect at the 5\% level was observed at multiple points around this station. Thus, we can infer that, since Moriya Station had become a transfer station between the TX and Joso lines, the opening of the TX line had a major impact on the increase in land prices around this station. However, the ITT in the area around Moriya Station weakened after 2009, which suggests that the treatment effect may not be permanent. The positive impacts are stronger in the north-west direction compared to the south-east direction from Moriya station. This suggests that a simple distance band dummy cannot fully capture the spatial benefit distribution. 
Furthermore, several points in the area around Tsukuba Station showed a significantly positive effect at 1\% in 2007, 2008, and 2009 and a significantly positive effect at 5\% in 2006, 2010, and 2011. Since Tsukuba Station has fewer trains arriving and departing than Moriya Station and it takes longer to get from there to central Tokyo (Seya et al., 2016), it likely saw relatively fewer benefits.

\section{Discussion}

The estimation results indicate that positive effects were observed at several sites. However, as stated in Section 1, the effect of additional infrastructure in a developed country whose infrastructure is already robust may only be redistributive, rather than generative. As expected, we obtain interesting results for the area around Toride Station, which is a transfer station for the Joban and Joso lines and also a terminus of the Joso line (see Figure 2). As the decrease in land prices in the area around Toride Station is relatively large, we expected that the opening of the TX line would negatively impact it by weakening its role as a transport node. From the changes in the average daily number of passengers from 2000 to 2010 (see Figure $12^{14}$ ), we observe a striking decrease in the average daily number of passengers at the JR Toride Station in the two years after it began operation (2005-2006). Interestingly, our analysis also reveals a significant positive treatment effect at several sites in the area around Toride Station at the 5\% level from 2006 to 2009 and at the 10\% level in 2010 and 2011. That is, even amid the downward trend in land prices, the opening of the TX line had a positive effect on those sites around Toride Station and helped control price drops. Since the opening of the TX line did not directly improve access to central Tokyo via public transport, such increases in land prices around Toride Station are likely the result of increased route options to central Tokyo. A review article on the option and non-use values of rail projects by Laird, Geurs, and Nash (2009) noted that, while the evidence base is small, the importance of option and non-use values is significant. Our results add empirical evidence of the importance of increased options.

As discussed in Section 1, Seya et al. (2016) indicated that a drop in land prices was observed in Tsuchiura city in the areas along the Joban line, but their clustering-based method could not test the statistical significance of this drop. For example, from the 2007 results in Figure 7, we can see that Tsukuba city experienced a positive effect overall, but Tsuchiura city suffered a negative overall impact, except for the area in front of Tsuchiura Station. However, the degree of these impacts is not statistically significant. That is, even if the areas along the Joban line suffered negative spillovers due to the fewer passengers, this is still fairly small in comparison to a decline caused by economic trends. ${ }^{15}$ Meanwhile, several points in the area around Ryugasaki Station on the Kanto Tetsudo Ryugasaki line consistently suffered significant negative effects at the 10\% level between 2006 and 2011. Suburban development has caused land prices in the area in front of Ryugasaki Station to decline and the opening of the TX line may have further worsened this situation. However, it is difficult to accurately identify the underlying reason from this analysis alone. Nonetheless, these results can serve as a basis for long-term urban planning. Points along the JR Joban line other than Toride Station also experienced significantly positive effects, albeit inconsistently, over the observation period, especially the areas around Ishioka Station (5\% significance level), Tsuchiura Station (10\% significance level), Ushiku Station (10\% significance level), and Ryugasakishi Station (Ryugasaki City; 10\% significance level). However, unlike the results for the areas around Tsukuba Station, Moriya Station, and Toride Station, these areas only had one significant result each, so there is room for debate as to whether this effect was due to the opening of the TX line.

\footnotetext{
14 The numbers of embarking and disembarking passengers include similar information; thus, we employ the number of embarking passengers.

15 In Figure 12, there is a decline at Tsuchiura Station in the two years after it opened in addition to the usual downward trend.
} 
Using the hedonic approach, Tsutsumi and Seya (2009) estimated the benefits of the opening of the TX line, employing data on the change in accessibility. For accessibility data, they used the distance between a given land observation site and its nearest railway station and the distance and duration from the nearest railway station to central Tokyo (Tokyo Station). We illustrate their analysis in Figure 13. According to this analysis, the opening of the TX line was predicted to bring positive benefits to the areas along the Joso line, as it would shorten the time and distance to reach Tokyo Station, although there was actually no benefit. In contrast to this type of ex-ante forecast, our ex-post analysis reveals that almost all sites along the Joso line experienced a positive effect between 2007 and 2011, although the effect was not significant. Furthermore, there was a significantly positive effect at the $10 \%$ level at Shimodate Station (Chikusei), which is a terminus of the Joso line, from 2008 to 2010. These results suggest that the positive effect that the opening of the TX line had on the Joso line (by forming a node with the TX line at Moriya Station) also spread to the areas along the Joso line. Meanwhile, along the Joban line, a positive effect, albeit insignificant, was observed at many points around Ushiku Station, and a negative effect, also insignificant, was observed between 2007 and 2011 at many points in Tsuchiura. Sites along the Joban line experienced both positive and negative effects and, in general, the effects were weak. Moreover, passenger numbers dropped in both Ushiku and Tsuchiura, which shows that changes in passenger numbers do not necessarily move in line with changes in land prices.

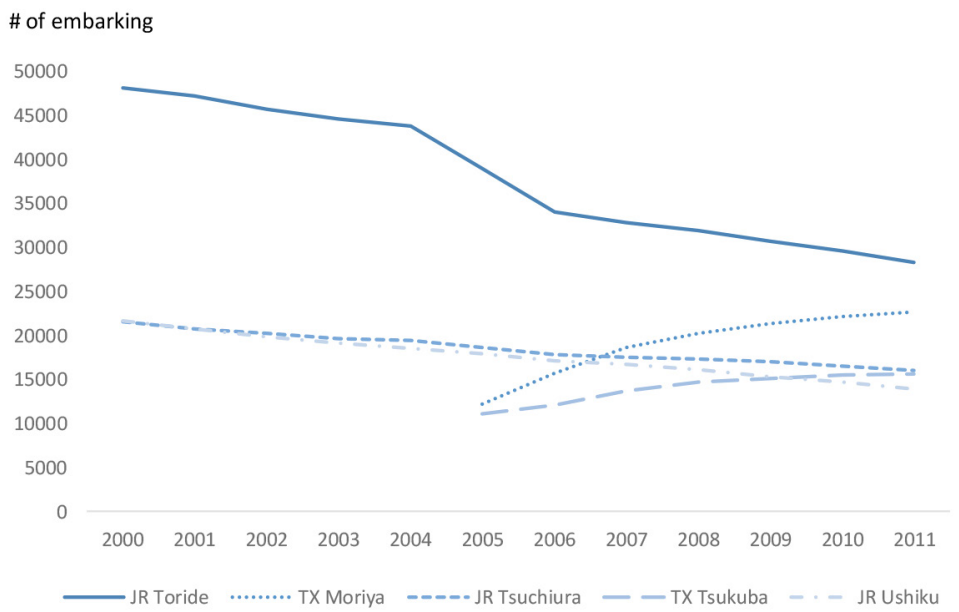

Figure 12. Average daily number of embarking passengers from 2000 to 2010 at each railway station 


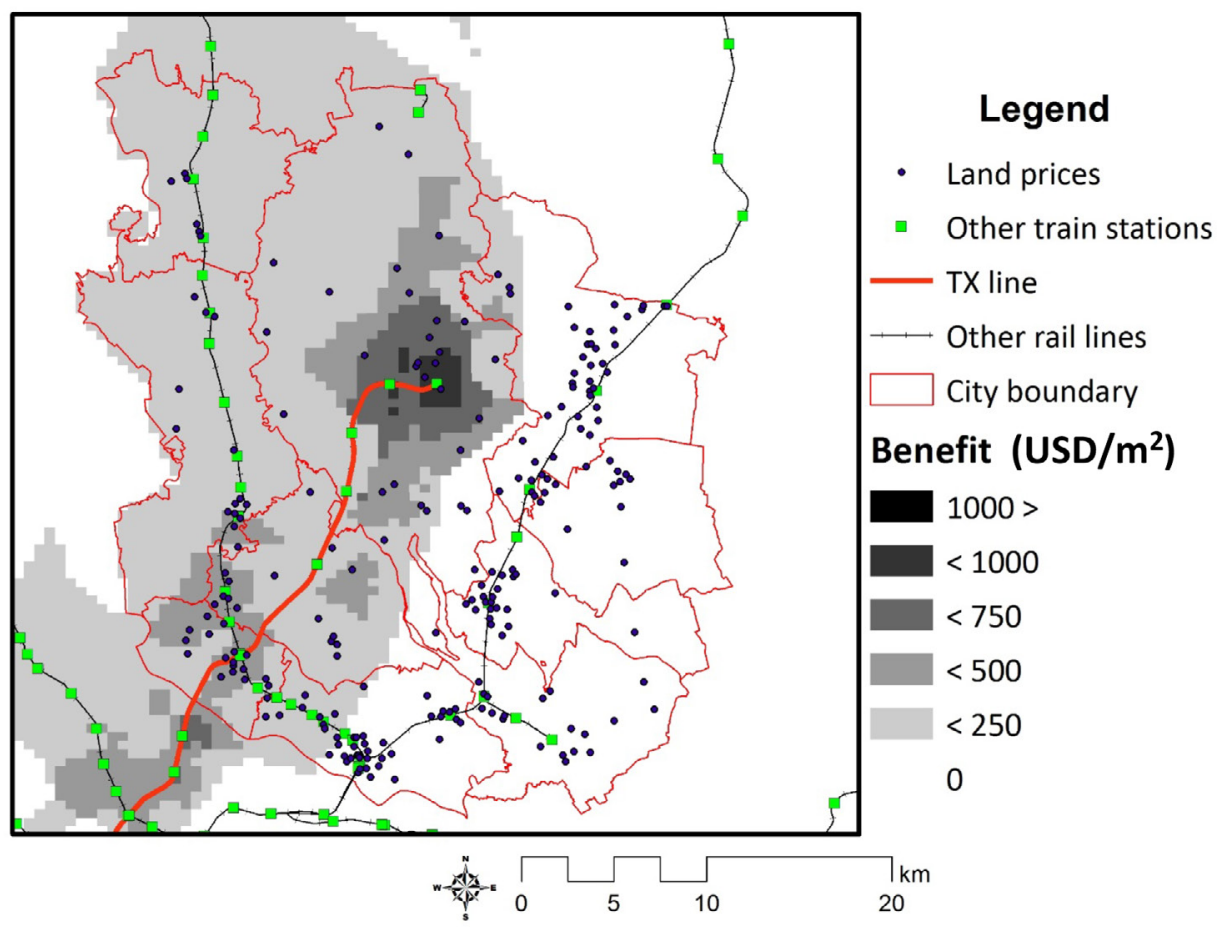

Figure 13. Benefit evaluation results using the hedonic approach of Seya et al. (2016)

\section{$5 \quad$ Concluding remarks}

This study proposes an approach for the ex-post identification of the geographical extent of an area benefiting from a transportation project. It employs the GSC method proposed by Xu (2017) to estimate the ITT (i.e., unit-level) and its uncertainty. The TX line project, a large-scale Japanese heavy railway, is selected as a case study. The findings from the case study are as follows.

First, plotting the p-value for ITT for each fiscal year on a map enables us to understand at a glance how the effect of the opening of the TX line was spatially distributed. Many points showed a significantly positive effect at the $1 \%$ level at TX Moriya Station (which is a transfer station for the TX and Joso lines) and in the area around Tsukuba Station (which is a terminus of the TX line). This effect partially weakened over the observation period but otherwise lasted throughout, showing that the opening of the TX line continued to have a positive treatment effect on these areas. This finding is consistent with the areas that were expected to experience a greater treatment effect from the opening of the TX line due to changes in accessibility (Tsutsumi \& Seya, 2009). Consequently, improvements in transport access can be interpreted as being capitalized into land prices. The spatial patterns of the ITT p-values are intricate. However, their major effects can be captured by existing accessibility indicators and dummy ranges of distance from railway stations (see Section 1) when their average effects are analyzed. Even so, a summary measure such as the ATT can also be estimated using the GSC method, as shown in Figures 3 and 4.

Nevertheless, some points in the area around Toride Station (the transfer station between the Joso and Joban lines), as well as in the area around Moriya Station (the transfer station between the Joso and TX lines), experienced significantly positive effects. This observation indicates the importance of transfer stations, particularly in the case of Toride Station, where the opening of the TX line did not directly improve access to central Tokyo via public transport. Increases in land prices around Toride Station are 
likely the result of increased options for routes to central Tokyo. Such increases due to increased options are worthy of examination, as they are rarely considered in ex-ante benefit evaluations using the hedonic approach (e.g., Tsutsumi \& Seya, 2009). In their review of the option and non-use values of rail projects, Laird et al. (2009) noted that whilst the evidence base is small, the importance of option and non-use values is large for projects involving the provision of commuting opportunities. Our results add empirical evidence of the importance of increased options.

This study also demonstrates the advantages of using the GSC method in analyzing the spatial benefit incidence of an infrastructure project. Although we analyze the case study of a particular railway project, the proposed procedure can be applied to many other countries and cases. Generally, how the effect of opening a new line manifests in an area changes greatly depending on how the characteristics of the area and the flow of its users change. Hence, further studies are needed to confirm the generalizability of our findings.

We suggest two directions for future research. First, this study only analyzes the sites for which data on land prices were obtained consecutively over the target period. However, the sites covered in publicly available land price data are often replaced. Moreover, slight changes in the position of a site would exclude it from the analysis. Furthermore, there are many sites with data available for only the post-event period. The method used in this study must be extended to such data. Second, we use the GSC method, but it is essential to examine the applicability of other methods, such as original synthetic control (Abadie, Diamond, \& Hainmueller, 2010) and matrix completion (Athey, Bayati, Doudchenko, Imbens, \& Khosravi, 2018), for comparative analyses.

\section{Acknowledgment}

This study was funded by the JSPS KAKENHI Grant Number 19H02262 and 20H02274, and the Advanced Road Technology Committee of the Ministry of Land, Infrastructure, Transport and Tourism. We are grateful for the constructive comments from Professor Atsushi Koike and Toshimori Otazawa of Kobe University, and Shota Fujishima of Hitotsubashi University.

\section{Appendix}

Appendix A: Map of changes from 2006-2008 available at https://www.jtlu.org/index.php/jtlu/article/ view/1784 


\section{References}

Abadie, A., Diamond, A., Hainmueller, J. (2010). Synthetic control methods for comparative case studies: Estimating the effect of California's tobacco control program. Journal of the American Statistical Association, 105(490), 493-505.

Ahsan, H. M., Nakamura, H., \& Ueda, T. (2001). A land use-transport model: The structure and applications. Journal of Civil Engineering, 29(2), 219-235.

Athey, S., Bayati, M., Doudchenko, N., Imbens, G., \& Khosravi, K. (2018). Matrix completion methods for causal panel data models (No. w25132). Cambridge, MA: National Bureau of Economic Research.

Bai, J. (2009). Panel data models with interactive fixed effects. Econometrica, 77(4), 1229-1279.

Cameron, T. A. (2006). Directional heterogeneity in distance profiles in hedonic property value models. Journal of Environmental Economics and Management, 51(1), 26-45.

Cervero, R., \& Landis, J. (1995). The transportation-land use connection still matters. Access, 7, 2-11.

Debrezion, G., Pels, E., \& Rietveld, P. (2007). The impact of railway stations on residential and commercial property value: A meta-analysis. The Journal of Real Estate Finance and Economics, 35(2), 161-180.

Dubé, J., Thériault, M., \& Des Rosiers, F. (2013). Commuter rail accessibility and house values: The case of the Montreal South Shore, Canada, 1992-2009. Transportation Research Part A, 54, 49-66.

Ewing, R. (2008). Highway-induced development: Research results for metropolitan areas. Transportation Research Record, 2067, 101-109.

Geng, B., Bao, H., \& Liang, Y. (2015). A study of the effect of a high-speed rail station on spatial variations in housing price based on the hedonic model. Habitat International, 49, 333-339.

Gibbons, S., \& Machin, S. (2005). Valuing rail access using transport innovations. Journal of Urban Economics, 57(1), 148-169.

Handy, S. (2005). Smart growth and the transportation-land use connection: What does the research tell us? International Regional Science Review, 28(2), 146-167.

Kawada, M., Okamoto, N., Ishida, H., \& Tsutsumi, M. (2010). Effects of the Tsukuba Express Project on the residents' travel behavior. Journal of the Eastern Asia Society for Transportation Studies, 8, 539-547.

Kuminoff, N. V., \& Pope, J. C. (2014). Do “Capitalization effects" for public goods reveal the public's willingness to pay? International Economic Review, 55(4), 1227-1250.

Laird, J., Geurs, K., \& Nash, C. (2009). Option and non-use values and rail project appraisal. Transport Policy, 16(4), 173-182.

Mizutani, C. (2012). Construction of an analytical framework for polygon-based land use transition analyses. Computers, Environment and Urban Systems, 36(3), 270-280.

Morisugi, H., \& Ohno, E. (1992). A benefit incidence matrix for urban transport improvement. Papers in Regional Science, 71(1), 53-70.

Morisugi, H., \& Ohno, E. (1995). Proposal of a benefit incidence matrix for urban development projects. Regional Science and Urban Economics, 25(4), 461-481.

Padeiro, M., Louro, A., \& da Costa, N. M. (2019). Transit-oriented development and gentrification: A systematic review. Transport Reviews, 39(6), 733-754.

Pior, M. Y., \& Shimizu, E. (2001). GIS-aided evaluation system for infrastructure improvements: Focusing on simple hedonic and Rosen's two-step approaches. Computers, Environment and Urban Systems, 25(2), 223-246.

Pior, M. Y., Shimizu, E., \& Nakamura, H. (1998). GIS-aided benefit evaluation system for urban 
railway improvements: Focusing on hedonic approach. Theory and Applications of GIS, 6(2), 11-22. Seya, H., \& Timmermans, H. (2018) An overview of Asian studies on transport and land use. In Junyi Zhang and Cheng-Min Feng (Eds.), Routledge Handbook of Transport in Asia (pp. 314-336). London: Routledge.

Seya, H., Yoshida, T. \& Tsutsumi, M. (2016). Ex-post identification of geographical extent of benefited area by a transportation project: Functional data analysis method. Journal of Transport Geography, 55, $1-10$.

Shimizu, C., \& Nishimura, K. (2006). Biases in appraisal land price information: The case of Japan. Journal of Property Investment \& Finance, 24(2), 150-175.

Sorensen, A. (2001). Subcentres and satellite cities: Tokyo's 20th century experience of planned polycentrism. International planning studies, 6(1), 9-32

Tsutsumi, M., \& Seya, H. (2008). Measuring the impact of large-scale transportation project on land price using spatial statistical models. Papers in Regional Science, 87(3), 385-401.

Tsutsumi, M., \& Seya, H. (2009). Hedonic approaches based on spatial econometrics and spatial statistics: Application to evaluation of project benefits. Journal of Geographical Systems, 11(4), 357-380.

Xu, Y. (2017). Generalized synthetic control method: Causal inference with interactive fixed effects models. Political Analysis, 25(1), 57-76.

Yamagata, Y., \& Seya, H. (Eds.). (2019). Spatial analysis using big data: Methods and urban applications. Cambridge, MA: Academic Press. 